MANDATORY VERSUS VOLUNTARY DISCLOSURE OF PRODUCT RISKS

A. Mitchell Polinsky

Steven Shavell

WORKING PAPER 12776 
NBER WORKING PAPER SERIES

MANDATORY VERSUS VOLUNTARY DISCLOSURE OF PRODUCT RISKS

\author{
A. Mitchell Polinsky \\ Steven Shavell \\ Working Paper 12776 \\ http://www.nber.org/papers/w12776
}

NATIONAL BUREAU OF ECONOMIC RESEARCH
1050 Massachusetts Avenue
Cambridge, MA 02138

December 2006

Stanford Law School and Harvard Law School, respectively. Both authors are also Research Associates of the National Bureau of Economic Research. Polinsky's research was supported by the John M. Olin Program in Law and Economics at Stanford Law School, and Shavell's by the John M. Olin Center for Law, Economics, and Business at Harvard Law School. We are grateful to Andrew Daughety, Andrew Postlewaite, Jennifer Reinganum, and Kathryn Spier for helpful comments and to David C. Thompson for able research assistance. The views expressed herein are those of the author(s) and do not necessarily reflect the views of the National Bureau of Economic Research.

(C) 2006 by A. Mitchell Polinsky and Steven Shavell. All rights reserved. Short sections of text, not to exceed two paragraphs, may be quoted without explicit permission provided that full credit, including (C) notice, is given to the source. 
Mandatory Versus Voluntary Disclosure of Product Risks

A. Mitchell Polinsky and Steven Shavell

NBER Working Paper No. 12776

December 2006

JEL No. D18,D62,D82,H23,K13,L15

\begin{abstract}
$\underline{\text { ABSTRACT }}$
We analyze a model in which firms are able to acquire information about product risks and may or may not be required to disclose this information. We initially study the effect of disclosure rules assuming that firms are not liable for the harm caused by their products. Although mandatory disclosure obviously is superior to voluntary disclosure given the information about product risks that firms possess -- since such information has value to consumers -- voluntary disclosure induces firms to acquire more information about product risks because they can keep silent if the information is unfavorable. The latter effect could lead to higher social welfare under voluntary disclosure. The same results hold if firms are liable for harm under the negligence standard of liability. Under strict liability, however, firms are indifferent about revealing information concerning product risk, and mandatory and voluntary disclosure rules are equivalent.
\end{abstract}

\author{
A. Mitchell Polinsky \\ Stanford Law School \\ Stanford University \\ Stanford, CA 94305 \\ and NBER \\ polinsky@stanford.edu \\ Steven Shavell \\ Harvard Law School \\ 1575 Massachusetts Avenue \\ Hauser Hall 508 \\ Cambridge, MA 02138 \\ and NBER \\ shavell@law.harvard.edu
}




\title{
Mandatory versus Voluntary Disclosure of Product Risks
}

\author{
A. Mitchell Polinsky and Steven Shavell
}

\section{Introduction}

Disclosure of information by firms about the risks of their products is of potential social value because it may help consumers decide whether to purchase the products and how best to use them. Firms, however, will not want to reveal unfavorable information about product risks — as that would reduce demand and the prices they could charge — although they will have an incentive to reveal favorable information. The motive of firms to suppress bad information about product risks is countered to an extent by regulations requiring the disclosure of information (such as those promulgated by the Food and Drug Administration, the Federal Trade Commission, and the Consumer Product Safety Commission ${ }^{1}$ ) and by the threat of liability for nondisclosure (an issue, for example, in pharmaceutical, medical device, automobile, and tobacco litigation ${ }^{2}$. . Yet as some observers have suggested, disclosure requirements and liability for nondisclosure also have an undesirable effect — they reduce the incentive of firms to acquire information about product risks in the first place (through research, product testing, and the

(C) 2006 A. Mitchell Polinsky and Steven Shavell. All Rights Reserved.

${ }^{1}$ For example, the Food and Drug Administration requires written "safety reports” for new drug investigations concerning "[a]ny adverse experience associated with the use of the drug that is both serious and unexpected" or "[a]ny finding from tests in laboratory animals that suggests a significant risk for human subjects ...” See 21 C.F.R. § 312.32 . The Federal Trade Commission "ensures both the accuracy of safety information provided by product sellers and that material safety information is provided.” See Petty (1995, p. 408). The Consumer Product Safety Commission "requires hazardous household products . . . to bear labeling that alerts consumers to the potential hazards that those products present." See U.S. Consumer Product Safety Commission, Office of Compliance, "Requirements under the Federal Hazardous Substances Act: Labeling and Banning Requirements for Chemicals and Other Hazardous Substances, 15 U.S.C. § 1261 and 16 C.F.R. Part 1500,” (August 2002), p. 1 (available at <http://www.cpsc.gov/businfo/ regsumfhsa.pdf>, last accessed October 5, 2006).

${ }^{2}$ See Alex Berenson, “At Vioxx Trial, a Discrepancy Appears to Undercut Merck's Defense,” The New York Times, July 20, 2005, section C, column 2, p. 1 (pharmaceutical litigation); Barry Meier, "Papers Show Guidant Considered Warning Doctors of Hazards,” The New York Times, June 7, 2006, section C, column 2, p. 1 (medical device litigation); Larry Kramer, "Ford Ignored Safety, Prosecutor Says," The Washington Post, January 16, 1980, First Section, p. A4 (automobile litigation); and David Johnston, "Federal Thrust Against Tobacco Gets New Vigor," The New York Times, March 18, 1996, section A, p. 1 (tobacco litigation). 
like ${ }^{3}$ ). Indeed, if disclosure obligations significantly chill firms' investment in information about risks, the obligations could be rendered largely self-defeating because firms would have little information that they could disclose.

Against this background, we analyze a model in which firms can acquire information about product risks and may or may not face disclosure obligations. We present the basic assumptions and framework of analysis in section 2 below. Firms, which have market power, decide whether to invest resources to acquire information about the risk that their products will fail and cause harm to consumers. The demand curve that a firm faces depends on the information that consumers have about the riskiness of its product. If information is not disclosed by a firm, consumers will rely on statistical information about product risks and make appropriate rational inferences from the firm's nondisclosure. Social welfare is the value of products to consumers minus the harm that they bear, the cost of production, and the cost of acquiring information about product risk.

In section 3 we evaluate the regimes of voluntary and mandatory disclosure when firms are not liable for the harm caused by their products. We begin with this case in order to understand the pure effect of disclosure obligations.

Under voluntary disclosure, firms reveal any favorable information about product risk that they have, so that they can obtain a higher price, but they do not disclose unfavorable information, to avoid having to accept a lower price. Although consumers will make a negative inference from a firm's silence and lower their demand for its good, the reduction will be limited

\footnotetext{
${ }^{3}$ To obtain a sense of how significant product safety research is, note that annual expenditures by biopharmaceutical companies on research and development, the majority of which concerns product testing, were $\$ 51.3$ billion in 2005. See Pharmaceutical Industry Profile 2006, pp. 2-4 (available at <http://www.phrma. org/files/2006\%20Industry\%20Profile.pdf>, last accessed October 5, 2006). It also has been estimated that annual spending by the top twenty drug manufacturers on drug safety monitoring after drug approval was \$800 million in 2003. See Ridley et al. (2006, pp. 431-32).
} 
by the fact that the firm's silence could be due to its not having acquired information rather than to its having decided not to reveal bad information. ${ }^{4}$ A firm's incentive to acquire information will reflect its ability to keep silent if the information turns out to be unfavorable.

Under mandatory disclosure, firms reveal all information about product risks that they have. Thus, if a firm is silent, the explanation must be that it did not acquire information about product risk; silence does not result in a negative inference about risk. A firm's incentive to acquire information now will reflect its inability to keep silent if the information turns out to be unfavorable. Hence, the value to a firm of information about risk will be lower under mandatory disclosure than under voluntary disclosure, and less information will be obtained.

Either disclosure regime could result in greater social welfare. Although mandatory disclosure obviously is superior to voluntary disclosure given the information about product risks that firms have — since such information has value to consumers — voluntary disclosure will induce firms to acquire more information about product risks because they can keep silent if the information is unfavorable. The latter effect could lead to higher social welfare under voluntary disclosure. The logic is as follows. Because firms acquire more information under voluntary disclosure, the likelihood that favorable information will be revealed will rise, even though no unfavorable information will be disclosed. If the social benefit from the more frequent revelation of favorable information outweighs the detriment due to silence about unfavorable information, voluntary disclosure could be superior (the cost of the additional information also needs to be taken into account).

In section 4 we reconsider mandatory and voluntary disclosure when firms are liable for the harm caused by their products, according to the negligence rule or strict liability. Under the

\footnotetext{
${ }^{4}$ For this reason, firms with information will not necessarily be led to reveal it in order to avoid a negative inference. For details, see the analysis of voluntary disclosure in section 3 below.
} 
negligence rule, firms are liable for harm only if they failed to take optimal care in the production of their products. Since they will be induced to take optimal care in order to avoid liability (at least in the simple model we study), they will turn out not to be found liable. Hence, the conclusions we reach are essentially the same as those in section 3. Firms only reveal favorable information under voluntary disclosure, and either voluntary or mandatory disclosure could be superior.

Under strict liability, firms are held liable for harm regardless of their level of care. Under this rule, consumers are not concerned about the occurrence of harm because they are assumed to be fully compensated for it. Hence, firms are indifferent about revealing information about product risk, and mandatory and voluntary disclosure rules are equivalent. Firms do, though, use the information they have about risk in a desirable way: the prices they charge will reflect the risk of harm caused by their products and thus will beneficially influence consumer purchase decisions.

In section 5 we conclude with a discussion of how our analysis would be affected if consumers can influence the risk of harm through the precautions they exercise in their use of products (for instance, by taking a drug only with meals if that would lower the risk of adverse side-effects).

Previous literature of relevance to this article includes Grossman (1981) and Milgrom (1981), who first emphasized that parties would voluntarily disclose their information; in their models parties are assumed to possess information rather than to decide whether to acquire it. ${ }^{5}$ The articles that are most closely related to ours are Matthews and Postlewaite (1985), Farrell (1986), and Shavell (1994), because they consider both the acquisition and disclosure of product

\footnotetext{
${ }^{5}$ These and other articles on the disclosure of information are surveyed in chapter 5 of Bolton and Dewatripont (2005).
} 
information by firms. ${ }^{6}$ In Matthews and Postlewaite (1985), product information is free for firms to acquire, and for that reason firms are led to obtain it; they also always disclose information, even under voluntary disclosure. Thus, the main feature of a regime of voluntary disclosure that we emphasize — that firms keep silent about unfavorable information — does not arise in their model; nor, as noted, is the cost of information an issue. ${ }^{7}$ In Farrell (1986), product information is costly to acquire, is not always acquired, and firms do not disclose unfavorable information under voluntary disclosure. Moreover, in his model firms might acquire less information if disclosure is required, but there is no welfare comparison of disclosure rules. In Shavell (1994), product information also is costly to acquire, is not always obtained, and firms keep silent about unfavorable information under voluntary disclosure. Unlike here, however, mandatory disclosure is always superior to voluntary disclosure in Shavell's analysis, essentially because sellers have the socially correct incentive to acquire information due to the assumption that they are able to extract all surplus from consumers. None of the foregoing articles examines the effect of liability for harm on the incentive to acquire and disclose information. Our article also is informed by economically-oriented legal literature on the disclosure of risks, notably Kronman (1978), which emphasizes the possibility that disclosure obligations would reduce the incentive to obtain information about risks.

\footnotetext{
${ }^{6}$ There are other articles that address related issues. See, for example, Daughety and Reinganum (2005), dealing with the incentive of firms involved in litigation over product-related injuries to settle and keep the riskiness of their products secret. See also Mathios (2000), who examines empirically how a switch from voluntary to mandatory disclosure affects consumer choices.

${ }^{7}$ An additional difference is that even though voluntary disclosure leads to information acquisition and complete disclosure, it still might not be socially desirable in their model because information could have negative value to consumers under their assumptions.
} 


\section{Framework of Analysis}

Consider a population of firms, each of which is a monopolist in its market and makes a product that may cause harm to consumers. ${ }^{8}$ The level of a firm's product risk is assumed to be unknown to the firm initially but can be ascertained by it at a cost. In particular, let

$$
\begin{aligned}
c & =\text { unit cost of making the good; } c \geq 0 ; \\
h & =\text { harm from the good; }{ }^{9} h \geq 0 ; \\
f(h) & =\text { probability density over } h ; f(h)>0 \text { in }\left[0, h_{M}\right] ;^{10} \\
k & =\text { cost to a firm of acquiring information about product risk; } k \geq 0 \text {; and } \\
t(k) & =\text { probability density over } k ; t(k)>0 .
\end{aligned}
$$

For simplicity, we assume that the harm $h$ is distributed independently among firms and that production cost $c$ is the same for all firms. A firm knows its cost of acquiring information $k$, and different firms face different $k$. If a firm does not acquire information, it only knows the distribution $f$ over $h$, whereas if it does spend $k$, it will learn $h$. If a firm learns $h$, it is able to credibly reveal $h$ to consumers. ${ }^{11}$

Two regimes of disclosure by firms are studied: mandatory disclosure of $h$; and voluntary disclosure of $h$.

\footnotetext{
${ }^{8}$ To assume that firms are perfect competitors rather than monopolists would be in tension with firms spending to acquire information about product risk: the free rider problem would discourage such spending, as any spending by one firm would benefit all of them since all would be selling the same product.

${ }^{9}$ We use the terms "harm" and "risk" interchangeably even though harm is treated as certain (alternatively, we could, without affecting our analysis, define $h$ to be the expected harm caused by a particular firm).

${ }^{10}$ The assumption that $h$ is bounded is needed to guarantee the existence of an equilibrium in the regime of voluntary disclosure. See the Appendix, part D.

${ }^{11}$ For example, the firm could make test results publicly available and have them attested to by a reputable independent entity.
} 
Firms decide whether to acquire information about $h$, whether to reveal $h$ when disclosure is voluntary, and what price to charge, so as to maximize expected profits, as will be described below.

A consumer obtains utility from having at most a single unit of the product, and this value varies among consumers. Let

$v=$ value of a unit of the product to a consumer; and

$s(v)=$ probability density over $v ; v \geq 0$,

where $s(v)$ is assumed to be the same for the products of different firms. ${ }^{12}$ The density $s(v)$ generates a demand curve. Let

$p$ = price of the product; and

$$
d(p)=\text { demand given } p .
$$

It is apparent that $d(p)$ is given by $1-S(p)$, where $S$ is the cumulative distribution of $v$. We will refer to $d(p)$ as the gross demand curve, since to the degree that consumers bear losses from the product, their net demand will be lower than $d(p)$.

The losses that consumers expect to bear from the product depend on their knowledge of the product risk and on the possibility of firm liability, which could result in compensation for harm suffered.

Consumer knowledge about product risk $h$ is as follows. Consumers know the probability density $f$ of $h$, but cannot directly observe $h$, whether firms know $h$, or the cost $k$ to a firm of learning $h$. However, consumers learn $h$ if a firm reveals $h$. If a firm does not reveal $h$, consumers make a rational inference about $h$. This inference depends on whether disclosure is mandatory or voluntary. If disclosure is mandatory, consumers infer that the firm must not have

\footnotetext{
${ }^{12}$ It will be obvious that nothing essential hinges on this assumption.
} 
acquired information about $h$ — otherwise $h$ would have been revealed — meaning that $f$ must describe the probability density over $h$. If disclosure is voluntary, consumers infer that there are two possible reasons for nondisclosure: either the firm did not obtain information; or the firm did obtain information and chose not to disclose it. The particular implications of consumer inference under voluntary disclosure will be explained below.

Social welfare equals the value consumers obtain from consumption of products minus the harm they suffer from the products, production cost, and firms' cost of acquiring information.

We now describe socially best behavior, as a standard of comparison to what occurs under different disclosure rules and liability regimes. Consider a particular firm whose harm is $h$ and suppose that $h$ is known. Then it is desirable for a consumer to obtain the product if and only if $v \geq c+h .^{13}$ Consequently, social welfare from consumption of the product is

$$
W_{I}=\int_{0}^{h_{M}} \int_{c+h}^{\infty}(v-c-h) s(v) d v f(h) d h,
$$

where the subscript $I$ indicates that information about $h$ is available to consumers.

Now suppose that $h$ is not known, so that all that is known is $f$ and the expected harm $E(h)$. Hence, it is desirable for consumers to obtain the product if and only if $v \geq c+E(h)$, and social welfare is

$$
\begin{gathered}
W_{N}=\int_{c}^{\infty}(v-c-E(h)) s(v) d v, \\
c(h)
\end{gathered}
$$

where the subscript $N$ stands for no information about $h$.

The social value of information about $h$ is readily verified to be the sum of two positive terms,

\footnotetext{
${ }^{13}$ We suppose for concreteness that consumers obtain the product when they are indifferent, and we will make similar assumptions below without further comment.
} 


$$
W_{I}-W_{N}=\int_{0}^{E(h)} \int_{c+h}^{c+E(h)}(v-c-h) s(v) d v f(h) d h+\int_{E(h)}^{h_{M} c+h} \int_{c+E(h)}^{c}(c+h-v) s(v) d v f(h) d h .
$$

The first term is the value of favorable information, that is, when $h$ is less than $E(h)$, in which case more consumers obtain the product and enjoy the surplus $v-c-h$ (those with $v$ in $[c+h$, $c+E(h)])$. The second term is the value of unfavorable information, when $h$ exceeds $E(h)$, in which case fewer consumers obtain the product and thus avoid the loss $c+h-v$ (those with $v$ in $[c+E(h), c+h])$.

A firm should obtain information if and only if its cost $k$ is less than or equal to (3).

In sum, we have

Remark 1. The socially best outcome is as follows:

(a) If information about product risk $h$ is acquired by a firm, consumers should obtain the product if and only if their value $v$ is at least $c+h$.

(b) If information about $h$ is not acquired, consumers should obtain the product if and only if their value $v$ is at least $c+E(h)$.

(c) The social value of information is given by (3) and is due to additional consumption when the information is favorable $(h<E(h))$ and to reduced consumption when the information is unfavorable $(h>E(h))$.

(d) A firm should acquire information about $h$ if and only if the firm's cost of acquisition $k$ is less than or equal to the social value of information (3)..

\section{Mandatory versus Voluntary Disclosure in the Absence of Liability}

We now examine and compare mandatory and voluntary disclosure when firms are not liable for harm. 
Mandatory disclosure. Under this regime, if a firm invests in information and learns the product risk $h$, the firm must disclose $h$ to consumers. ${ }^{14}$

To determine outcomes, suppose first that a firm acquires information about $h$. Then, since $h$ must be revealed, consumers will make a purchase if and only if $v \geq p+h$. In other words, the effective demand curve of consumers is $1-S(p+h)$ and is lower than $d(p)$; we will refer to this demand curve as $d_{h}(p)$. The firm will then set the profit-maximizing price at $p(h)$, where marginal revenue equals marginal $\operatorname{cost} c$, and will make a corresponding level of profits. Let

$\pi(h)=$ firm's profit when the harm is $h$ and the demand curve is $d_{h}(p)$.

Now suppose that a firm does not acquire information about $h$. Then consumers view the harm they suffer as $E(h)$, and so will make a purchase if and only if $v \geq p+E(h)$. The demand curve faced by a firm will thus be $d_{E(h)}(p)=1-S(p+E(h))$, the price will be $p(E(h))$, and profits will be $\pi(E(h))$.

The value of information to a firm under mandatory disclosure is

$$
E(\pi(h))-\pi(E(h))
$$

which is positive (see the Appendix, part A). Firms will acquire information when $k$ is less than or equal to (4).

To summarize, we have

Proposition 1. Suppose that disclosure of product risk is mandatory and that there is no liability for product harm. Then:

(a) If a firm acquires information $h$, the firm will disclose it and charge the price $p(h)$.

\footnotetext{
${ }^{14}$ We assume that the state is able to determine (at least with some probability) whether a firm possesses information about product risk, in order to enforce disclosure obligations. We do not consider regulation of firms' choices whether to acquire information about $h$. Such regulation would not be feasible if the state is unable to observe a firm's cost $k$ of acquiring information.
} 
(b) If a firm does not acquire information, consumers will view the expected harm as $E(h)$ and the firm will charge the price $p(E(h))$.

(c) Firms acquire information if and only if their cost $k$ is less than or equal to the private value of information (4).

This outcome diverges from the socially optimal outcome in two respects. First, consumers purchase too little because of monopoly pricing: the price, $p(h)$ or $p(E(h))$, exceeds $c$, so that too few consumers buy the product, given the available information about harm.

Second, the value to firms of information about product risk (4) is generally different from the social value of information about product risk (3). We would expect the private value to be lower, and thus for there to be too little acquisition of information, because firms are not able to extract the full surplus from consumers. This intuition is borne out, for example, in the case of linear demand (see the Appendix, part B). It is possible, however, for the private value of information to exceed the social value, because the fraction of consumer surplus that the monopolist is able to capture could increase when information becomes available (see the Appendix, part C).

Voluntary disclosure. Under the voluntary disclosure regime, if a firm acquires information and learns the product risk $h$, it can decide whether to reveal $h$.

To determine outcomes under this regime, assume first that a firm acquires information and reveals $h$. Then, as before, the demand curve of consumers will be $d_{h}(p)$, and the firm will set the price at $p(h)$ and earn profits of $\pi(h)$.

Suppose alternatively that a firm does not disclose $h$, either because it decides not to disclose that it knows $h$ or because it does not know $h$. A firm's situation will be the same in 
both cases, since consumers are assumed to be unable to distinguish between them. ${ }^{15}$ Consumers then view the harm they suffer as $E(h \mid N)$, the expected harm conditional on nondisclosure, so will make a purchase if and only if $v \geq p+E(h \mid N)$. The demand curve faced by a firm will thus be $d_{E(h \mid N)}(p)$, the price will be $p(E(h \mid N))$, and profits will be $\pi(E(h \mid N))$.

Next consider the choice of a firm that acquires information about $h$ whether to disclose it. If the firm does not disclose $h$, it will make a profit of $\pi(E(h \mid N))$, whereas if it discloses $h$, it will make a profit of $\pi(h)$. Since $\pi$ is strictly decreasing in $h$, the firm will disclose $h$ if and only if $h<E(h \mid N)$, that is, if and only if information is favorable. ${ }^{16}$

We can now compute the value of information to a firm. If the firm acquires information, we know from the preceding paragraph that its expected profit is

$$
\int_{0}^{E(h \mid N)} \pi(h) f(h) d h+(1-F(E(h \mid N)) \pi(E(h \mid N)),
$$

where $F$ is the cumulative distribution of $h$. If a firm does not obtain information about $h$, it makes profit of $\pi(E(h \mid N))$. Let

$$
\eta=\text { value of information to a firm under voluntary disclosure. }
$$

Hence,

$$
\eta=\int_{0}^{E(h \mid N)}[\pi(h)-\pi(E(h \mid N))] f(h) d h,
$$

\footnotetext{
${ }^{15}$ Firms that did not acquire information about $h$ would wish to indicate this fact to consumers if they could. This observation raises the question whether a firm could warrant that it does not know $h$ by contracting with, say, an independent auditor to certify that it did not acquire information. We assume that such warranties are not feasible because the entities hired to do the certifying are unable to discover whether a firm possesses information about product risk. This assumption is in some tension with our assumption that the state is able to determine whether a firm possesses information about product risk in a mandatory disclosure regime. However, the state has powers for learning facts that are unavailable to private parties (notably the ability to compel testimony under oath and to issue subpoenas backed by the threat of criminal sanctions). model.

${ }^{16}$ Note that "favorable" information is endogenous to the model, since $E(h \mid N)$ is determined within the
} 
that is, the extra profit that the firm obtains when $h$ turns out to be favorable. This must be positive since, as noted above, $\pi$ is strictly decreasing in harm. Firms will acquire information when $k$ is less than or equal to $\eta$.

Finally, we will verify that an equilibrium value of the expectation $E(h \mid N)$ exists. Let $q=$ likelihood of a firm not having information conditional on nondisclosure.

The likelihood of nondisclosure is

$$
(1-T(\eta))+T(\eta)(1-F(E(h \mid N))
$$

where $T$ is the cumulative distribution of $k$. Hence,

$$
q=(1-T(\eta)) /[(1-T(\eta))+T(\eta)(1-F(E(h \mid N))]
$$

$E(h \mid N)$ must satisfy

$$
E(h \mid N)=q E(h)+(1-q) E(h \mid h \geq E(h \mid N))
$$

since, as we have explained, firms that know $h$ do not disclose it if and only if $h \geq E(h \mid N)$. Note that (9) implicitly involves $E(h \mid N)$ through $q$ (including because $\eta$ is a function of $E(h \mid N)$ ), as well as explicitly. Equation (9) is the equilibrium condition: if $E(h \mid N)$ satisfies (9), then if firms and individuals believe $E(h \mid N)$, their belief will in fact be correct, and conversely. We show in the Appendix, part D, that a solution $E(h \mid N)$ to (9) exists.

Observe from (9) and from the fact that $E(h \mid h \geq E(h \mid N))>E(h)^{17}$ that $E(h \mid N)$ must exceed $E(h)$, reflecting the relatively high expected harm of firms that acquire information but choose not to disclose it.

To summarize, we have

Proposition 2. Suppose that disclosure of product risk is voluntary and that there is no liability for product harm. Then:

\footnotetext{
${ }^{17}$ This follows from the general point that $E(h \mid h>z)>E(h)$ for any $z>0$ in the support of $h$, since the density $f$ of $h$ is positive on $[0, z]$.
} 
(a) If a firm acquires information $h$ and $h$ is favorable — less than $E(h \mid N)$ - then the firm will disclose $h$ and charge the price $p(h)$, but if $h$ is unfavorable — equals or exceeds $E(h \mid N)$ then the firm will keep silent and charge the price $p(E(h \mid N))$.

(b) If a firm does not acquire information, consumers will view the expected harm as $E(h \mid N)$ and the firm will charge $p(E(h \mid N))$.

(c) Firms acquire information if and only if their cost $k$ is less than the private value of information (6).

This outcome diverges from the socially optimal one in two general respects. First, consumer purchases may be suboptimal for several different reasons. If a firm learns $h$ and discloses it, too little may be purchased due to monopoly pricing. If a firm learns $h$ and does not disclose it, then too little may be purchased due to monopoly pricing, or too much because consumers underestimate harm — they believe the expected harm is $E(h \mid N)$, whereas the true $h$ is higher. ${ }^{18}$ Additionally, if a firm does not learn $h$, then too little is purchased not only because of monopoly pricing, but also because consumers overestimate expected harm — they believe it is $E(h \mid N)$, whereas expected harm actually is lower, $E(h)$.

Second, the private value of information (6) is generally different from the social value (3), for essentially the reasons discussed in the case of mandatory disclosure (see the Appendix, parts E and F).

Comparison of mandatory and voluntary disclosure. We first claim that the private value of information about product risk is higher under voluntary disclosure (6) than under mandatory disclosure (4). This follows from two observations. First, if a firm learns $h$, its expected profits must be higher under voluntary disclosure: the firm makes greater profits than

${ }^{18}$ The problem of excessive purchase occurs if $p(E(h \mid N))+E(h \mid N) \leq v<c+h$. 
$\pi(h)$ when $h$ exceeds $E(h \mid N)$ and it is silent about $h$, whereas under mandatory disclosure the firm makes only $\pi(h)$ for such $h$; when $h$ does not exceed $E(h \mid N)$ and the firm reveals $h$, the firm makes $\pi(h)$ under both voluntary and mandatory disclosure. Second, if a firm does not acquire information about $h$, its profit will be lower under voluntary disclosure: the firm makes $\pi(E(h \mid N))$, whereas under mandatory disclosure it makes the higher amount $\pi(E(h))$. Thus, the private value of information is higher under voluntary disclosure not only because a firm’s expected profit is higher when it acquires information, but also because its profit is lower when it does not.

Social welfare may be either higher or lower under voluntary disclosure of product risks (see the Appendix, parts $\mathrm{G}$ and $\mathrm{H}$ ). The explanation is as follows. Mandatory disclosure involves two social advantages relating to better consumer purchase decisions. First, when firms acquire information about $h, h$ is revealed to consumers, so their purchasing decisions are perfectly informed. Under voluntary disclosure, $h$ is not revealed to consumers if $h$ is unfavorable, in which case their purchasing decisions are not perfectly informed — they may purchase the good when they should not because they do not know that $h$ is unfavorable.

Second, when firms do not obtain information about $h$ under mandatory disclosure, consumers believe correctly that the expected harm is $E(h)$, so that their purchasing decisions are correct given that firms do not know $h$. Under voluntary disclosure, however, consumers believe that the expected harm is $E(h \mid N)>E(h)$, so their purchasing decisions are not correctly informed — they may refrain from purchasing when they should, because they think nondisclosure is a worse signal than it is in fact for firms with no information about $h$.

However, voluntary disclosure has an advantage over mandatory disclosure relating to firms' incentives to acquire information. As we explained, the private value of information 
about $h$ is higher under voluntary disclosure, so more firms will obtain information than under mandatory disclosure. Some of the firms that would not have obtained information under mandatory disclosure will learn that $h$ is favorable and thus disclose this information. When this happens, consumers will make purchase decisions based on knowledge of $h$, whereas they would not have known $h$ under mandatory disclosure (they would only have known $E(h)$ ). Thus, some consumers who should purchase the product will do so, even though they would not have under mandatory disclosure.

The comparison between the regimes can now be summarized.

Proposition 3. The differences between voluntary and mandatory disclosure regimes are as follows:

(a) If a firm acquires information $h$ and $h$ is unfavorable — exceeds $E(h \mid N)$ - then the firm will keep silent under voluntary disclosure, and consumers will believe the expected harm to be $E(h \mid N)$, but the firm will disclose $h$ under mandatory disclosure.

(b) If a firm does not acquire information about $h$, then consumers will believe the expected harm to be $E(h \mid N)$ under voluntary disclosure and $E(h)$ under mandatory disclosure.

(c) The value of information under voluntary disclosure (6) exceeds that under mandatory disclosure (4).

(d) Social welfare could be higher under either voluntary disclosure or mandatory disclosure.

One may view the possible superiority of voluntary disclosure over mandatory disclosure as stemming from the problem that the private value of information is likely to be socially inadequate under mandatory disclosure (see the comments following Proposition 1). Because 
the private value of information is higher under voluntary disclosure, voluntary disclosure can be regarded as an implicit means of correcting for this problem.

\section{Disclosure under Liability Rules}

We now reexamine disclosure of product risks when firms may be held liable for losses caused by their products. We analyze the two major rules of liability — negligence and strict liability.

Negligence. Under the negligence rule, a firm is held liable for harm only if its level of care was below a legally determined standard of care. To consider this rule, we need to add to the model a variable corresponding to costly care in the manufacture of the product. ${ }^{19}$ Let

$$
x=\text { level and cost of firm care per unit of the good; and }
$$$$
r(x)=\text { probability of harm given } x ; r^{\prime}(x)<0 \text { and } r^{\prime \prime}(x)>0 \text {. }
$$

We assume for simplicity that $x$ is chosen by a firm before it obtains information about harm $h$. Thus, the socially optimal $x$ minimizes the sum of the expected harm and the cost of care, $r(x) E(h)+x$, for each unit of the good. Call this $x^{*}$. We assume that courts set the standard of care at $x^{*}$, so firms are held liable for harm only if their care $x$ was below $x^{*}$. It is readily shown that this rule will induce firms to choose $x *{ }^{20}$

Because firms are led to choose optimal care $x^{*}$ and therefore are not in fact liable for harm, the analysis of disclosure under the negligence rule is essentially identical to that in the

\footnotetext{
${ }^{19}$ Note that we are discussing negligence in relation to the manufacture of the good — not negligence in regard to a duty to disclose information.

${ }^{20}$ For $x<x^{*}$, a firm's cost per unit is $x+q(x) E(h)$ because it is liable. For $x \geq x^{*}$, a firm's cost per unit is just $x$ because it is not liable. Clearly, $x=x^{*}$ will be preferred to any higher $x$. And since for $x<x^{*}, x+q(x) E(h)>$ $x^{*}+q\left(x^{*}\right) E(h)>x^{*}, x^{*}$ also will be preferred to any lower $x$. This is a standard result in the literature on liability for accidents. See, for example, Shavell (1987, pp. 33-36).
} 
absence of liability, except that where we previously referred to harm $h$ or expected harm $E(h)$, we now refer to $r\left(x^{*}\right) h$ or $r\left(x^{*}\right) E(h)$. Thus, we have

Proposition 4. Under the negligence rule, firms are led to take optimal care and therefore are not held liable for harm due to their products. Hence, Propositions 1-3 continue to hold.m

Strict liability. Under this rule, a firm is held liable for harm regardless of the level of care that it exercised. Thus, for each unit of the product, the firm's expected liability and cost of care is $r(x) E(h)+x$, and it will choose optimal care $x^{*}$ to minimize this sum.

Since consumers know that they will be compensated for any harm $h$ that they suffer, the magnitudes of $h$ and $r(x)$ will not matter to them; their net demand curve will equal their gross demand curve $d(p) .{ }^{21}$ Consequently, firms will be indifferent about revealing $h$, and the regimes of mandatory and voluntary disclosure will thus be equivalent.

Because demand for the product will not depend on consumer knowledge of product risk, the private value of information to firms is calculated differently from before. If a firm does not obtain information about $h$, its per unit cost will be $c+r\left(x^{*}\right) E(h)+x^{*}$, and the firm will choose the profit-maximizing price given this marginal cost and the demand curve $d(p)$. Its resulting profit again can be denoted $\pi(E(h))$, but with the understanding that the argument $E(h)$ now refers to a parameter of the firm's cost function rather than of the consumers' demand curve. If a firm does obtain information, it will know that its per unit cost will be $c+r\left(x^{*}\right) h+x^{*}$, so it will set a different price, resulting in profit $\pi(h)$. In other words, prices will be different when firms obtain information about $h$, not because demand will change, but rather because firms then will know their actual liability cost instead of just their expected liability cost. The value of information to a firm therefore will be $E(\pi(h))-\pi(E(h))$, as in (4), but with the different

\footnotetext{
${ }^{21}$ If consumers can take precautions to reduce expected harm, they may want to know about product risk under strict liability. See section 5 .
} 
interpretation of the profit function stated above. The private value of information to a firm may be either higher or lower than the social value, for reasons analogous to what we discussed in section 3, but we would expect the private value to be lower.

We summarize as follows.

Proposition 5. Under strict liability, firms are led to take optimal care. Because consumers and firms are indifferent about revelation of product risk information, mandatory and voluntary disclosure are equivalent. Firms have a positive incentive to obtain information, which could be socially inadequate or socially excessive.n

As was observed, consumer decisions are influenced by firms’ information about product risk because the prices firms charge reflect the information they obtain. Interestingly, this influence operates both when the information is favorable and when it is unfavorable, in contrast to the case of voluntary disclosure in the absence of liability, when unfavorable information is not revealed by firms and does not directly influence consumer purchases.

\section{Concluding Remarks}

A factor that we did not analyze in the model is that information about product risk may have value to consumers because it may influence the precautions they employ in their use of products, such as taking a drug only with meals to reduce the chance of an adverse side-effect, or driving a particular type of car slowly in snow because of its tendency to skid.

If we incorporated consumer precautions into our model, the analysis of disclosure in the absence of liability would include the point that consumers' precautions would be optimal given their information, as they would bear their losses. Moreover, because information about product risk would benefit consumers by allowing them to take precautions that reflect risk, firms would 
have an added incentive to acquire and disclose information. But firms still would not want to disclose sufficiently unfavorable information, and the value of information under voluntary disclosure still would be higher than under mandatory disclosure. Hence, the qualitative results we found would carry over, and either the mandatory or the voluntary disclosure regime could be preferable.

Similarly, our analysis of negligence would be essentially unchanged. Again, if the standard of care under the negligence rule is chosen optimally, firms would meet the standard and not be found liable, so the situation would turn out to be the same as in the absence of liability.

Under strict liability, however, there would be two notable differences due to the issue of consumer precautions. First, as is well known in the economic analysis of liability, a pure strict liability rule would lead consumers to exercise inadequate care because they would be fully compensated for their losses. To remedy this problem, a defense of contributory negligence would need to be employed, under which firms would not be held liable if consumers failed to meet a standard of care applicable to them. This defense would induce consumers to take proper precautions given their information. Second, firms would not be indifferent with respect to the disclosure of information about product risk, as they were in the setting in section 4 . They would now have a motive to disclose even unfavorable information. In essence, this is because the firm not only pays for the harm to consumers (it is strictly liable), it also implicitly bears the cost of consumer precautions (since demand falls to the extent consumers undertake precautions). Hence, the firm should want to minimize the expected harm plus the costs of precautions, and for consumers to be induced to take the optimal level of precautions, they must know the level of harm. 


\section{Appendix}

In this appendix we demonstrate several results claimed in section 3 when firms are not liable for causing harm.

\section{A. Proof that the private value of information is positive under mandatory disclosure.}

Let $p^{\prime}=p(E(h))$ be a firm's price if it does not acquire information and $q^{\prime}=d_{E(h)}\left(p^{\prime}\right)$.

Suppose the firm learns $h$, discloses it, sets the price $\rho(h)$ so that quantity is always $q^{\prime}$, that is, $d_{h}(\rho(h))=q^{\prime}$. We claim that $E(\rho(h))=p^{\prime}$. Now by definition of the demand curves, we know that $q^{\prime}=1-S\left(p^{\prime}+E(h)\right)$ and $d_{h}(\rho(h))=1-S(\rho(h)+h)$. And since $q^{\prime}=d_{h}(\rho(h))$, we must have $p^{\prime}+E(h)=\rho(h)+h$. Taking the expected value of each side, we obtain, $p^{\prime}+E(h)=$ $E(\rho(h))+E(h)$, implying the claim. The claim means that the firm would make the same profit if it discloses $h$ and sets the price at $\rho(h)$ as when it does not have information: for its expected revenue would be the same (the claim), and its production cost would be $q^{\prime} c$ in both cases. But the firm can obviously make greater profits by disclosing $h$ and choosing $p(h)$ instead of $\rho(h)$, so the value of information must be positive.

\section{B. Proof that the private value of information equals one-half of the social value under} mandatory disclosure if demand is linear.

Let the demand curve be linear, with an inverse demand curve given by $p=k_{1}-k_{2} q$, where $k_{1}$ and $k_{2}$ are positive constants.

To compute the social value of information, observe that in the absence of information about $h$, social welfare equals the area between the demand curve and the full social cost of the product, $c+E(h)$, which is $\left(k_{1}-c-E(h)\right)^{2} / 2 k_{2}$. If information about $h$ is acquired, social welfare given $h$ is $\left(k_{1}-c-h\right)^{2} / 2 k_{2}$. Hence, the social value of information is 


$$
\left[\int_{0}^{h_{M}}\left(k_{1}-c-h\right)^{2} f(h) d h / 2 k_{2}\right]-\left[\left(k_{1}-c-E(h)\right)^{2} / 2 k_{2}\right] .
$$

Now consider the private value of information. If information about $h$ is not acquired, it is easily verified that the firm's profit is $\pi(E(h))=\left(k_{1}-c-E(h)\right)^{2} / 4 k_{2}$, whereas if $h$ is learned, the firm's profit given $h$ is $\pi(h)=\left(k_{1}-c-h\right)^{2} / 4 k_{2}$. Hence, the private value of information is

$$
\left.\underset{0}{h_{M}}\left(k_{1}-c-h\right)^{2} f(h) d h / 4 k_{2}\right]-\left[\left(k_{1}-c-E(h)\right)^{2} / 4 k_{2}\right],
$$

which is half of (A1).

\section{Example in which the private value of information under mandatory disclosure}

\section{exceeds the social value.}

We provide a discrete example, which could readily be converted into a continuous example (as can other discrete examples in other parts of the Appendix). ${ }^{22}$ Suppose that there are two types of individuals, a low-benefit type whose benefit is 5 and a high-benefit type whose benefit is 7 , with probabilities of .9 and .1, respectively, and that the level of harm is 4 or 6 , with probabilities of .8 and .2, respectively. Assume for simplicity that the cost of production is zero (it will be obvious that the result to be obtained would hold if production costs are positive but small).

To compute the social value of information, note that in the absence of information, the expected harm is $.8(4)+.2(6)=4.4$, so both types should obtain the product. Hence, social welfare is $.9(5-4.4)+.1(7-4.4)=.8$. If $h$ is learned and is 4 , then both types should obtain the product, whereas if $h$ is 6 , then only the high-benefit type should obtain it. Hence, social welfare

\footnotetext{
${ }^{22}$ The calculations in the examples are undertaken to a greater degree of precision than is reported. As a consequence, there are some slight inconsistencies in the reported numbers due to rounding error.
} 
is $.8[.9(5-4)+.1(7-4)]+.2[.1(7-6)]=.98$. Thus, the social value of information is $.98-.8=.18$.

To determine the private value of information, observe that if $h$ is not known, the lowbenefit type will obtain a net benefit from the product of $5-4.4=.6$ and the high-benefit type will obtain a net benefit of $7-4.4=2.6$. Hence, the firm will charge .6 and make a profit of .6 (rather than charge 2.6 and make a profit of .26). If the firm learns $h$ and it is 4 , then the net benefit of the low-benefit type is $5-4=1$ and that of the high-benefit type is $7-4=3$.

Therefore, the firm will charge 1 and make a profit of 1 . If $h$ is 6 , the firm will sell only to the high-benefit type, charge 1 , and obtain a profit of .1. Hence, the expected profit if information is obtained is $.8(1)+.2(.1)=.82$. The private value of information therefore is $.82-.6=.22$, which exceeds the social value of .18.

The explanation of why the private value of information exceeds the social value in this example is, in essence, that when the firm knows $h$ it is able to extract more of the surplus from the high-benefit types, but this source of private value is not associated with a social value.

\section{Proof that an equilibrium exists under voluntary disclosure.}

We want to show that there is a value of $E(h \mid N)$ that satisfies (9). For notational simplicity here, let $E(h \mid N)$ be represented by $z$, so we want to show that there is a $z$ satisfying

$$
[q(z) E(h)+(1-q(z)) E(h \mid h \geq z)]-z=0,
$$

where, recall, $q(z)$ is given by (8).

We first demonstrate that the left-hand side of (A3) is positive at $z=E(h)$ : Observe that $E(h \mid h \geq z)>E(h)$ for any $z>0$ in the support of $h$, since the density $f$ of $h$ is positive on $[0, z]$. Also, it is clear from (8) that $q(z)<1$ since $T(\eta)>0$ and $(1-F(z))>0$. Hence $(1-q(z))>0$. Thus, the term in brackets exceeds $E(h)$, implying that the left-hand side is positive. 
Now observe that the limit of the left-hand side of (A3) as $z$ approaches $h_{M}$ is negative: Let $\eta_{M}$ be the limit of $\eta$ as $z \rightarrow h_{M}$; it is apparent from (6) that this limit exists. From (8), the limit of $q(z)$ as $z \rightarrow h_{M}$ is $\left(1-T\left(\eta_{M}\right)\right) /\left(1-T\left(\eta_{M}\right)\right)=1$. Thus, since $E(h \mid h \geq z)$ is bounded by $h_{M}$, the limit of the left-hand side of (A3) as $z \rightarrow h_{M}$ is $E(h)-h_{M}<0$.

Since the left-hand side of (A3) is a continuous function of $z$, it must equal zero somewhere between $E(h)$ and $h_{M \cdot}{ }^{23}$

\section{E. Example in which the private value of information under voluntary disclosure is}

\section{less than the social value.}

Since we employ a discrete example similar to that in part C, our discussion here will be abbreviated. There are two types of individuals, whose benefits are 5 and 7 with probabilities of .6 and .4, respectively, and levels of harm of 4 or 6 with probabilities of .45 and .55 , respectively.

First consider the social value of information. In the absence of information about harm, the expected harm is 5.1, so only high-benefit types should obtain the product. Hence, social welfare is $.4(7-5.1)=.76$. If there is information about $h$ and it equals 4 , both types should have the product, whereas if $h$ is 6 , then only the high-benefit type should have it. Hence, social welfare is $.45[.6(5-4)+.4(7-4)]+.55[.4(7-6)]=1.03$. The social value of information is thus $1.03-.76=.27$.

We next calculate the private value of information. As discussed in the text, the private value of information under voluntary disclosure depends upon $E(h \mid N)$, which must be endogenously determined. To this end, let the cost $k$ of acquiring information be .2 and 1 with equal probability. We will now compute $E(h \mid N)$ on the provisional assumption that only the lowcost firms acquire information and that they disclose $h$ only if it is 4 . This assumption will be

\footnotetext{
${ }^{23}$ However, (A3) might equal zero at more than one point; thus, the equilibrium might not be unique. None of our results would be affected if there are multiple equilibria under voluntary disclosure.
} 
shown to be consistent with the behavior of firms. The fraction of firms that do not disclose information because they do not acquire it is .5 (those whose $k$ is 1 ), while the fraction of firms that do not disclose information because they discovered unfavorable information is .5(.55) $=$ .275 (those whose $k$ is .2 and who learn that the harm is 6). Thus, the likelihood of a firm not having information conditional on nondisclosure, $q$, is .5/(.5 +.275) $=.645$. The expected harm conditional on information being unfavorable, $E(h \mid h \geq E(h \mid N))$, is 6. Thus, applying (9), $E(h \mid N)=$ $.645(5.1)+.355(6)=5.42$.

Now suppose that a firm does not acquire information. Then the low-benefit individuals will not purchase the product because $E(h \mid N)$ is 5.42, exceeding their benefit of 4 . The highbenefit types will obtain a net benefit of $7-5.42=1.58$. Hence, the firm will charge 1.58 and obtain an expected profit of $.4(1.58)=.632$.

Finally, observe that if a firm acquires information, since $E(h \mid N)=5.42$, it will reveal $h$ only if it is 4 . If $h$ is 4 , the net values of the low-benefit and high-benefit types are 1 and 3 , respectively. The firm will charge 3 and obtain a profit of 1.2. Since the firm will not reveal $h$ if it is 6 , the firm will make a profit of .632, as explained in the preceding paragraph. Thus, the firm's expected profit if it acquires information is $.45(1.2)+.55(.632)=.888$, and the private value of information is $.888-.632=.255$, which is less than the social value of .270 . Note, too, that since the private value of information is .255 , firms whose $k$ is .2 will acquire it, but firms whose $k$ is 1 will not, as assumed.

\section{F. Example in which the private value of information under voluntary disclosure} exceeds the social value.

We showed in section 3 that the private value of information under voluntary disclosure (6) exceeds that under mandatory disclosure (4). We provided an example in part $\mathrm{C}$ above in 
which the private value of information under mandatory disclosure exceeds the social value. Hence, were disclosure voluntary in that example, the private value of information also would exceed the social value.

\section{G. Example in which mandatory disclosure results in higher social welfare than} voluntary disclosure.

We will employ here the example from part C, assuming that firms' $k$ is equally likely to be .2 or 1 .

To compute social welfare under mandatory disclosure, recall from part $\mathrm{C}$ that the private value of information is .22. Hence, only low-cost firms will acquire it. For such firms social welfare is $.8[.9(5-4)+.1(7-4)]+.2[.1(7-6)]-.2=.78$, since, as seen above, both types of consumer purchase the product when $h$ is 4 and only the high-benefit types purchase the product when $h$ is 6 . For firms that do not acquire information, social welfare is $.9(5-4.4)+.1(7-4.4)$ $=.8$. Hence, social welfare under mandatory disclosure is $.5(.78)+.5(.8)=.79$.

To determine social welfare under voluntary disclosure, assume that only low-cost firms acquire information and that they disclose it only when $h$ is 4 , which will be shown to be consistent with the behavior of firms in equilibrium. Thus, the probability of nondisclosure due to the absence of information is .5, while the probability of nondisclosure due to the acquisition of unfavorable information is .5(.2) $=.1$. Accordingly, $q=.5 /(.5+.1)=.83$ and $E(h \mid N)=$ $.83(4.4)+.17(6)=4.67$.

Now consider the profit of a firm if it does not acquire information. The net benefit to the low-benefit types will be $5-4.67=.33$ and to the high-benefit types $7-4.67=2.33$. The firm would charge .33 and make a profit of .33 . 
If the firm acquires information and $h$ is 4 , the firm will disclose it. The net benefit to the low-benefit types will be $5-4=1$ and to the high-benefit types $7-4=3$. The firm will charge 1 and make a profit of 1.

If the firm acquires information and $h$ is 6 , the firm will not disclose it. The situation is then identical to that when the firm does not acquire information and its profit will be .33.

Thus, if the firm acquires information, its expected profit will be $.8(1)+.2(.33)=.87$. The private value of information under voluntary disclosure therefore is $.87-.33=.53$. Consequently, as we assumed, only firms whose $k$ is .2 will acquire information.

For firms that acquire information, social welfare is .8[.9(5-4)+.1(7-4)] $+.2[.9(5-6)$ $+.1(7-6)]-.2=.6$. For firms that do not acquire information, social welfare is $.9(5-4.4)+$ $.1(7-4.4)=.8$ Hence, social welfare under voluntary disclosure is $.5(.6)+.5(.8)=.7$, which is less than social welfare under mandatory disclosure. The explanation is that under both mandatory and voluntary disclosure, only low $k$ firms acquire information; since information is the same under both regimes, mandatory disclosure is preferable because it leads to better consumption decisions.

\section{H. Example in which voluntary disclosure results in higher social welfare than}

\section{mandatory disclosure.}

Modify the example just considered by assuming that the probabilities of $h$ being 4 and 6 are .25 and .75 , respectively, so $E(h)$ is 5.5 .

To calculate social welfare under mandatory disclosure, note that if no information is obtained, then the low-benefit types will not purchase the product because $E(h)$ of 5.5 exceeds their benefit of 5 . Hence, a firm will sell only to the high-benefit types, charge $7-5.5=1.5$, and make a profit of $.1(1.5)=.15$. If a firm acquires information and $h$ is 4 , the firm will charge 1 
and make a profit of 1 . If $h$ is 6 , the firm will sell only to the high-benefit types, charge 1 , and obtain a profit of $.1(1)=.1$. Hence, the expected profit if the firm acquires information is $.25(1)$ $+.75(.1)=.325$. The private value of information therefore is $.325-.15=.175$, so, since $k$ is either .2 or 1 , neither type of firm will acquire information. Consequently, social welfare is .1(7 $-5.5)=.15$

To ascertain social welfare under voluntary disclosure, assume that only low-cost firms acquire information and that they disclose it only when $h$ is 4 . Thus, the probability of nondisclosure due to the absence of information is .5, while the probability of nondisclosure due to the acquisition of unfavorable information is $.5(.75)=.375$. Hence, $q=.5 /(.5+.375)=.57$ and $E(h \mid N)=.57(5.5)+.43(6)=5.71$.

Now consider the profit of a firm if it does not acquire information. Given that $E(h \mid N)$ is 5.71, it can only sell to the high-benefit individuals, will charge $7-5.71=1.29$, and earn profits of .1(1.29) $=.129$.

If the firm acquires information and $h$ is 4 , the firm will disclose it. The net benefit to the low-benefit types is $5-4=1$ and to the high-benefit types is $7-4=3$. The firm will charge 1 and make a profit of 1 .

If the firm acquires information and $h$ is 6 , the firm will not disclose it. The situation is then identical to that when the firm does not acquire information and its profit will be .129. Thus, if the firm acquires information, its expected profit will be $.25(1)+.75(.129)=$ .346. The private value of information under voluntary disclosure therefore is .346-.129= .218. Consequently, firms whose $k$ is .2 will acquire information, but not firms whose $k$ is 1 , as assumed. 
For firms that acquire information, social welfare is .25[.9(5-4) +.1(7-4)] +.75[.1(7$6)]-.2=.175$. For firms that do not acquire information, social welfare is $.1(7-5.5)=.15$. Hence, social welfare under voluntary disclosure is $.5(.175)+.5(.15)=.163$, which exceeds social welfare under mandatory disclosure.

This result occurs for the following reason. Under mandatory disclosure, firms do not have an incentive to acquire information. Under voluntary disclosure, however, the value of information is higher and low-cost firms do acquire information. When the harm is low these firms disclose it, improving purchase decisions (because low types then purchase the product). 


\section{References}

Bolton, Patrick, and Mathias Dewatripont, Contract Theory (Cambridge, MA: MIT Press, 2005).

Daughety, Andrew F., and Jennifer F. Reinganum, “Secrecy and Safety,” American Economic Review, Vol. 95, No. 4 (September 2005), pp. 1074-1091.

Farrell, Joseph, "Voluntary Disclosure: Robustness of the Unraveling Result, and Comments on Its Importance,” in Ronald E. Grieson (Editor), Antitrust and Regulation (Lexington, MA: Lexington Books, 1986), pp. 91-103.

Grossman, Sanford J., “The Informational Role of Warranties and Private Disclosure of Product Quality,” Journal of Law and Economics, Vol. 24, No. 3 (December 1981), pp. 461-484.

Kronman, Anthony, “Mistake, Disclosure, Information, and the Law of Contracts,” Journal of Legal Studies, Vol. 7, No. 1 (January 1978), pp. 1-34.

Mathios, Alan D., “The Impact of Mandatory Disclosure Laws on Product Choices: An Analysis of the Salad Dressing Market,” Journal of Law and Economics, Vol. 43, No. 2 (October 2000), pp. 651-677.

Matthews, Steven, and Andrew Postlewaite, “Quality Testing and Disclosure,” RAND Journal of Economics, Vol. 16, No. 3 (Autumn 1985), pp. 328-340.

Milgrom, Paul R., “Good News and Bad News: Representation Theorems and Applications,” Bell Journal of Economics, Vol. 12, No. 2 (Autumn 1981), pp. 380-391.

Petty, Ross D., “Regulating Product Safety: The Informational Role of the U.S. Federal Trade Commission,” Journal of Consumer Policy, Vol. 18, No. 4 (December 1995), pp. 387-415. Ridley, David B., Judith M. Kramer, Hugh H. Tilson, Henry G. Grabowski, and Kevin A. Schulman, “Spending on Postapproval Drug Safety,” Health Affairs, Vol. 25, No. 2 (March/April 2006), pp. 429-436. 
Shavell, Steven, Economic Analysis of Accident Law (Cambridge, MA: Harvard University Press, 1987).

Shavell, Steven, “Acquisition and Disclosure of Information Prior to Sale,” RAND Journal of Economics, Vol. 25, No. 1 (Spring 1994), pp. 20-36. 